\title{
Relationship between door-to-embolization time and clinical outcomes after transarterial embolization in trauma patients with complex pelvic fracture
}

\author{
Hohyun Kim ${ }^{1,2,3}$. Chang Ho Jeon ${ }^{2,3,4}$. Jae Hun Kim 1,2,3 • Hoon Kwon ${ }^{2,3,4}$. Chang Won Kim ${ }^{2,3,4}$. Gil Hwan Kim ${ }^{1,2}$. \\ Chan Kyu Lee ${ }^{1,2}$. Sang Bong Lee ${ }^{1,2}$. Jae Hoon Jang ${ }^{2,3,5} \cdot$ Seon Hee Kim ${ }^{1,2,3} \cdot$ Chan Yong Park ${ }^{6} \cdot$ Seok Ran Yeom $^{2,3,7}$
}

Received: 3 June 2020 / Accepted: 2 January 2021 / Published online: 1 February 2021

(c) The Author(s) 2021

\begin{abstract}
Background While transarterial embolization (TAE) is an effective way to control arterial bleeding associated with pelvic fracture, the clinical outcomes according to door-to-embolization (DTE) time are unclear. This study investigated how DTE time affects outcomes in patients with severe pelvic fracture.

Methods Using a trauma database between November 1, 2015 and December 31, 2019, trauma patients undergoing TAE were retrospectively reviewed. The final study population included 192 patients treated with TAE. The relationships between DTE time and patients' outcomes were evaluated. Multiple binomial logistic regression analyses, multiple linear regression analyses, and Cox hazard proportional regression analyses were performed to estimate the impacts of DTE time on clinical outcomes.

Results The median DTE time was 150 min (interquartile range, 121-184). The mortality rates in the first $24 \mathrm{~h}$ and overall were $3.7 \%$ and $14.6 \%$, respectively. DTE time served as an independent risk factor for mortality in the first $24 \mathrm{~h}$ (adjusted odds ratio $=2.00,95 \%$ confidence interval $[\mathrm{CI}]=1.20-3.34, p=0.008)$. In Cox proportional hazards regression analyses, the adjusted hazard ratio of DTE time for mortality at 28 days was $1.24(95 \% \mathrm{CI}=1.04-1.47, p=0.014)$. In addition, there was a positive relationship between DTE time and requirement for packed red blood cell transfusion during the initial $24 \mathrm{~h}$ and a negative relationship between DTE time and ICU-free days to day 28.

Conclusion Shorter DTE time was associated with better survival in the first $24 \mathrm{~h}$, as well as other clinical outcomes, in patients with complex pelvic fracture who underwent TAE. Efforts to minimize DTE time are recommended to improve the clinical outcomes in patients with pelvic fracture treated with TAE.
\end{abstract}

Keywords Multiple trauma $\cdot$ Therapeutic embolization $\cdot$ Pelvic bone $\cdot$ Mortality rate $\cdot$ Time

Supplementary Information The online version contains supplementary material available at https://doi.org/10.1007/s0006 8-021-01601-7.

Jae Hun Kim

drtrauma73@gmail.com

Hohyun Kim

gskhh@naver.com

1 Department of Trauma Surgery and Surgical Critical Care, Pusan National University Hospital, 179 Gudeok-Ro, Seo-Gu, Busan 49241, Korea

2 Biomedical Research Institute, Pusan National University Hospital, Busan, Korea
3 Pusan National University School of Medicine, Yangsan-si, Gyeongsangnam-do, Korea

4 Department of Diagnostic Radiology, Pusan National University Hospital, Busan, Korea

5 Department of Orthopaedic Surgery, Pusan National University Hospital, Busan, Korea

6 Department of Trauma Surgery, Wonkwang University Hospital, Iksan-si, Jeollabuk-do, Korea

7 Department of Emergency Medicine, Pusan National University Hospital, Busan, Korea 


\section{Background}

The incidence of pelvic fracture in blunt trauma is as high as $10 \%$, with mortality ranging from 21 to $50 \%$ primarily owing to hemorrhagic shock $[1,2]$. Hemorrhage from pelvic vessels is a dreaded and potentially lethal condition of pelvic fractures [3, 4]. Pelvic transarterial embolization (TAE) is the most effective intervention for management of arterial hemorrhage associated with pelvic fracture [5-7]. TAE has come of age and has an important role in the treatment of patients with pelvic fracture, supported by the highest level of evidence [7-9]; for instance, pelvic angiography with embolization seems to be $85-97 \%$ effective for controlling bleeding $[6,8]$.

Delayed hemorrhage control may increase a patient's mortality risk with time; early angiography with embolization is associated with improved patient outcomes in patients with pelvic fracture [10-13]. However, many previous studies have shown that it is difficult to achieve this goal [14, 15].

The current study evaluated the impact of delays in performing pelvic TAE on patients' survival. We hypothesized that a larger door-to-embolization (DTE) time would be significantly associated with increased mortality in patients with complex pelvic fracture.

\section{Methods}

\section{Study setting}

In the Pusan National University Hospital Regional Trauma Center, there are more than 900-1,000 severe trauma-related admissions annually (Injury Severity Score [ISS] $\geq 16$ ), of which 200-250 patients present with pelvic fracture. Our institution is equipped with a trauma bay, a 42-bed dedicated trauma intensive care unit (ICU), and a trauma angiography suite. Three interventional radiologists and the equipment required for TAE are available $24 \mathrm{~h}$ a day, 7 days a week [16]. Thus, the time from arrival to angiography can be less than $2 \mathrm{~h}$. Patients with pelvic fractures without extrapelvic injuries requiring emergency treatment are treated according to the pelvic fracture management algorithm (Fig. 1). We classifies the patient's response to initial fluid resuscitation according to Advanced Trauma Life Support (ATLS) [17]. There are three possible patterns of response to the initial fluid bolus: rapid response, transient response, and minimal or no response. Indication for TAE is intrapelvic contrast extravasation or hematoma in a computed tomography scan or a transient responder with hemodynamic instability (HI) associated with pelvic fractures. If needed, TAE is also conducted after pelvic packing or any damage control operation or procedures (Fig. 1).

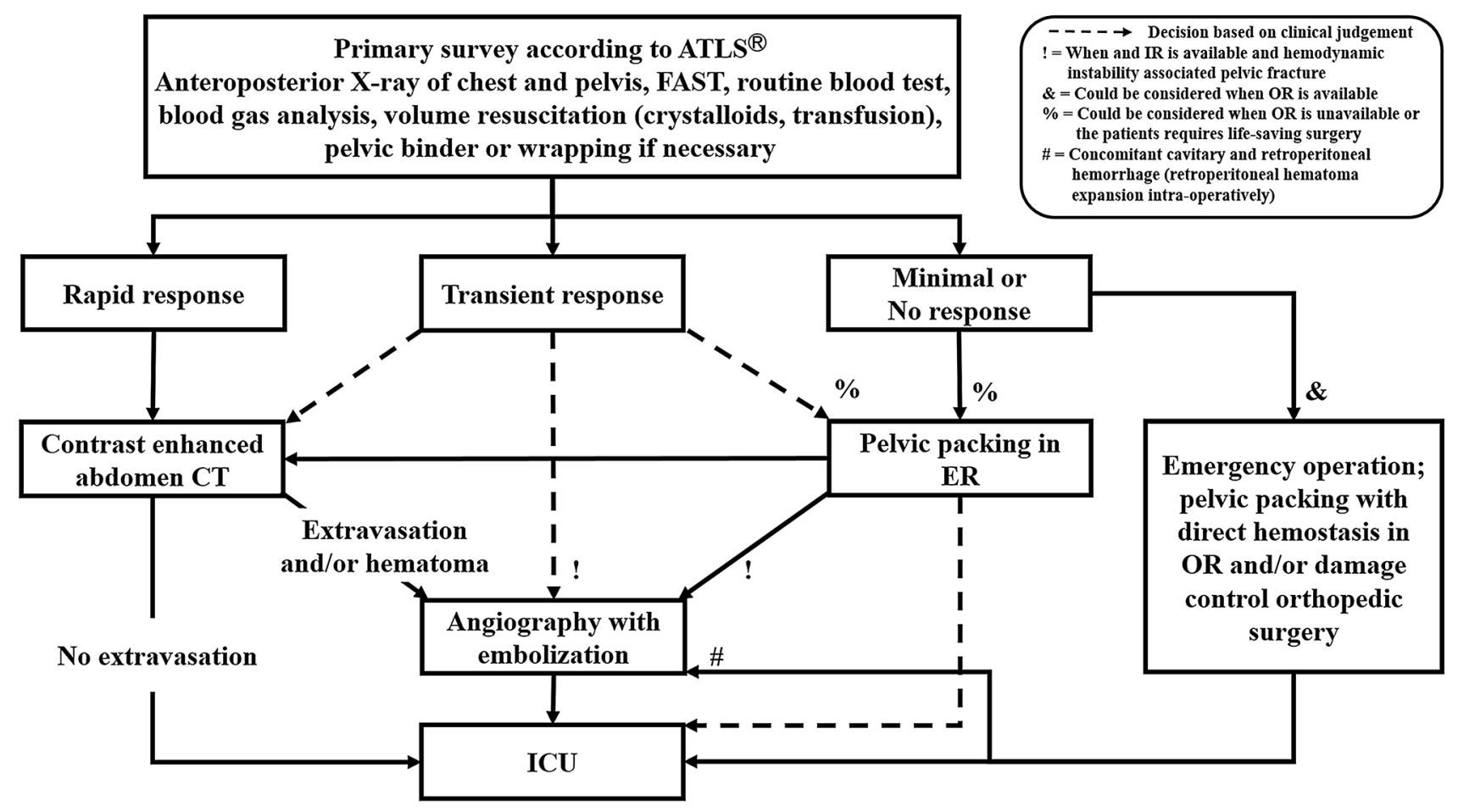

Fig. 1 Pelvic fracture management algorithm. ATLS adult trauma life support, FAST focused assessment with sonography in trauma, ER emergency room, $I R$ interventional room, $O R$ operating room, $I C U$ intensive care unit 


\section{Study population}

We retrospectively reviewed data from the medical records and included a total of 1017 patients with pelvic fracture admitted to the trauma resuscitation unit at our Trauma Center between November 1, 2015 and December 31, 2019. Inclusion criteria were adult patients ( $\geq 18$ years), ISS $\geq 16$, and patients with an the World Society of Emergency Surgery (WSES) classification of pelvis grade $\geq$ II (Table E1) [7]. Pelvic injuries almost always accompany injuries to other organ systems. Considering only isolated pelvic injuries would not be realistic; thus, polytraumatic patients with pelvic bone fracture were included in this study. Patients declared dead-on-arrival or discharged or transferred from a trauma resuscitation unit within $24 \mathrm{~h}$ or with unclear medical records, patients who did not undergo TAE, patients underwent preperitoneal packing (PPP) and/or pelvic external fixation, and patients underwent angiography more than $12 \mathrm{~h}$ after admission were excluded. PPP and/ or pelvic fixation were considered as hemostatic intervention, so patients underwent PPP and/or pelvic external fixation were excluded, because they can cause bias of results in this study. In addition, patients underwent angiography more than $12 \mathrm{~h}$ after admission were excluded, as they likely had delayed presentation of the indications for TAE or had prolonged periods of time with operative treatment of multiple injuries. The final study population included $192 \mathrm{TAE}$ patients (Fig. 2).

Available data included age, sex, mechanism of injury, vital sign on arrival, transfusion with packed red blood cells (pRBCs) within $4 \mathrm{~h}$ and $24 \mathrm{~h}$ of arrival, AIS, ISS, Glasgow Coma Scale score (GCS), Revised Trauma Score (RTS), shock index, Trauma and Injury Severity Score (TRISS), massive transfusion within initial $24 \mathrm{~h}$ of arrival, hospital length of stay, intensive care unit (ICU) stay, and survival status in the first $24 \mathrm{~h}$, at 28 days, and discharge. Massive transfusion was defined as the replacement by transfusion of 10 units of red blood cells in $24 \mathrm{~h}$.

\section{Definitions and outcome measures}

We defined DTE time as the time from the arrival at hospital to the first application of embolic agents such as polyvinyl alcohol, Gelfoam, coils, and so forth to pelvic arteries. We defined door-to-angiography (DTA) time as that from the arrival at the hospital to the beginning of angiography (Fig. 3). Complex pelvic fracture was defined as a pelvic fracture with WSES grade $\geq$ II in polytrauma patients (Table E1) [7]. The shock index was defined as heart rate (beat/min)/systolic blood pressure (SBP; $\mathrm{mmHg}$ ). HI was defined as $\mathrm{SBP}<90 \mathrm{mmHg}$ and $\mathrm{SI} \geq 1.0$ on arrival [18, 19]. Daytime was defined as 8:30 a.m. through 5:30 p.m.,

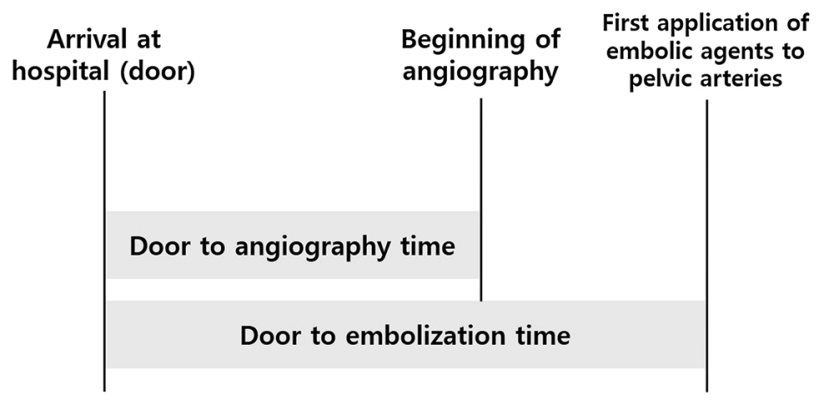

Fig. 3 Scheme for timeframe from injury onset to transarterial embolization in trauma patients with severe pelvic fracture
Fig. 2 Flowchart of the study. $E D$ emergency department, $T A E$ transarterial embolization

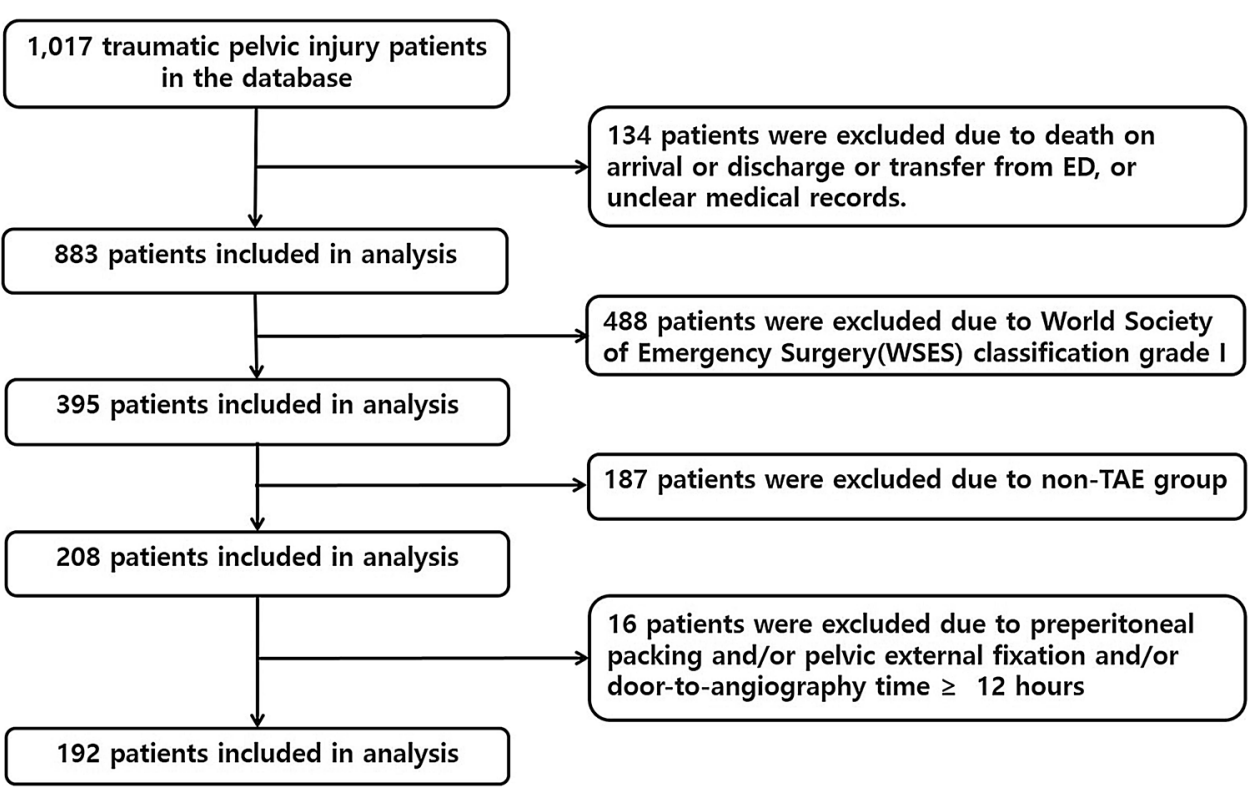


and the weekend was defined as 5:31 p.m. Friday through 08:29 a.m. Monday.

The primary outcomes were mortality in the first $24 \mathrm{~h}$. Secondary outcomes included overall mortality (in-hospital mortality), pRBC transfusion amounts during the initial $24 \mathrm{~h}$, ICU-free days to day 28 , and hospital-free days to day 90 . ICU-free days to day 28 were calculated as 28 minus the number of days or part-days in the ICU. All patients who died before the day 28 follow-up were counted as having zero ICU-free days, on the basis that they should be counted as having the worst possible outcome. Hospital-free days to day 90 are a composite of in-hospital death and hospital length of stay, defined as the number of days alive and out of the hospital between the index visit to the trauma resuscitation unit and 90 days later. Patients who died during the index hospitalization and those hospitalized for more than 90 days were classified as having zero hospital-free days. For patients discharged alive before day 90 , the number of hospital-free days was calculated as 90 minus the length of stay.

We divided the patients into two groups according to their DTE time ( $\leq 150 \mathrm{~min}$ vs. $>150 \mathrm{~min})$ to assess the effects of that on clinical outcomes. We arbitrarily set the cut-off point $(150 \mathrm{~min})$ at the median of the DTE time.

\section{Statistical analyses}

We present continuous variables as median and interquartile ranges and categorical variables as numbers and percentages. We compared categorical variables using the chi-square test when appropriate; otherwise, we used Fisher's exact test. We compared continuous variables with a Wilcoxon rank-sum test on the basis of the distribution. Multiple binomial logistic regression analyses were performed in a stepwise fashion, evaluating the effects on mortality of DTE time, and injury-to-embolization time. In addition to comparing survival in the first $24 \mathrm{~h}$ between DTE time and mortality, Kaplan-Meier plots of survival curves up to 28 days for each group were drawn and their differences were assessed using the log-rank test. We used Cox proportional-hazards model to estimate the hazard ratio of DTE time for mortality at day 28 by adjusting for compounding factors. We performed multiple linear regression analyses to estimate the impact of DTE time on ICU-free days to day 28 , hospital-free days to day 90 , and $24 \mathrm{~h} \mathrm{pRBC}$ transfusion requirement. A value of $p<0.05$ was declared to be statistically significant. The Statistical Package for the Social Sciences (Version 20.0, SPSS, Inc., Chicago, IL, USA) and STATA software (Version 14.2, Stata Corp., College Station, TX, USA) were used to analyze the data.

\section{Results}

\section{Demographics of patients with severe pelvic fracture undergoing TAE}

The median DTA time was 108 min (interquartile range [IQR], 78-134). DTA time was not significantly different between daytime and nighttime (98 min [IQR, 73-134] vs. $112 \min$ [IQR, 86-135], $p=0.067$ ) or between weekday and weekend or holiday (101 min [IQR, 77-133] vs. 113 min [IQR, 82-139], $p=0.156$ ). The median DTE time was $150 \mathrm{~min}$ (IQR, 123-186). The median age was 58 years (IQR, $41-70$ ), and $45.3 \%$ were female. The median ISS was 33 (IQR, 25-41) and 32.3\% had HI. Most patients had associated severe injuries (AIS $\geq 3$ ), with head and neck (27.1\%), thoracic (54.7\%), and abdominal (34.9\%) injuries occurring most commonly. The median ICU-free days to day 28 and hospital-free days to day 90 were 21 days (IQR, 3-26) and 48 days (IQR, 0-63), respectively. The median $24 \mathrm{~h}$ transfusion requirements were five packs (IQR, 2-11) of pRBCs. In addition, the mortality rates in the first $24 \mathrm{~h}$ and overall were $3.7 \%$ and $15.7 \%$, respectively. The demographics of the patients with complex pelvic fracture undergoing TAE are shown in Table 1. The characteristics of patients died within $24 \mathrm{~h}$ of hospital admission is demonstrated in Table E2.

\section{Risk factors for mortality in the first $\mathbf{2 4} \mathrm{h}$ (Table 2)}

In univariate analyses, factors associated with mortality in the first $24 \mathrm{~h}$ of patients with complex pelvic fracture were DTE time, DTA time, heart rates upon admission, GCS, TRISS, and pRBC transfusion amounts in the initial $24 \mathrm{~h}$. Considering clinical priority and statistical significance, we finally selected 6 confounding factors (age, gender, SBP upon arrival, ISS, GCS, and pRBC transfusion amounts during the initial $24 \mathrm{~h}$ ) in multiple binomial logistic analysis. After adjusting for the six variables, DTE time was an independent risk factor for mortality in the first $24 \mathrm{~h}$. An increase of $1 \mathrm{~h}$ in DTE time resulted in a 2.00fold increase in mortality in the first $24 \mathrm{~h}$.

Cox proportional hazards regression analyses were performed to evaluate the independent risk factors for mortality at 28 days. After adjusting for age, SBP upon arrival, ISS, GCS, TRISS, and pRBC transfusion amounts during the initial $24 \mathrm{~h}$, the adjusted hazard ratio of DTE time was 1.24. This means that an increase of $1 \mathrm{~h}$ in DTE time resulted in a 1.24-fold increase in mortality at 28 days. 
Table 1 Characteristics of patients treated with transarterial embolization $(n=192)$

\begin{tabular}{|c|c|}
\hline Characteristics & Variable \\
\hline $\begin{array}{l}\text { Door-to-angiography time, median (IQR), } \\
\text { min }\end{array}$ & $106(78-134)$ \\
\hline $\begin{array}{l}\text { Door-to-embolization time, median (IQR), } \\
\text { min }\end{array}$ & $150(121-184)$ \\
\hline \multicolumn{2}{|l|}{ Origin of admission, $n(\%)$} \\
\hline Scene & $92(47.9)$ \\
\hline Transfer & $100(52.1)$ \\
\hline \multicolumn{2}{|l|}{ Time of admission } \\
\hline Weekday or day, $n(\%)$ & $58(30.2)$ \\
\hline Weekend or night or holiday, $n(\%)$ & $134(69.8)$ \\
\hline Age, median (IQR), years & $58(41-70)$ \\
\hline Female, $n(\%)$ & $87(45.3)$ \\
\hline \multicolumn{2}{|l|}{ Injury mechanism, $n(\%)$} \\
\hline Car TA & $13(6.8)$ \\
\hline Motorcycle TA & $19(9.9)$ \\
\hline Pedestrian TA & $69(35.9)$ \\
\hline Fall & $67(34.9)$ \\
\hline Entrapment & $12(6.2)$ \\
\hline Others & $12(6.2)$ \\
\hline \multicolumn{2}{|l|}{ Physiology at admission } \\
\hline $\begin{array}{l}\text { Systolic blood pressure, median (IQR), } \\
\mathrm{mmHg}\end{array}$ & $90(70-100)$ \\
\hline Heart rate, median (IQR), beats/min & $94(80-113)$ \\
\hline Shock index, median (IQR) & $1.0(0.8-1.4)$ \\
\hline Hemodynamic instability, $n(\%)$ & $62(32.3)$ \\
\hline Lactic acid, median (IQR), mmol/L & $3.8(2.4-6.3)$ \\
\hline Base excess, median (IQR) & $-4.0(-7.6$ to -0.9$)$ \\
\hline ISS, median (IQR) & $33(25-41)$ \\
\hline GCS, median (IQR) & $15(11-15)$ \\
\hline RTS, median (IQR) & $7.33(6.38-7.84)$ \\
\hline TRISS score, median (IQR) & $0.83(0.62-0.94)$ \\
\hline \multicolumn{2}{|l|}{ WSES grade, $n(\%)$} \\
\hline II & $25(13.0)$ \\
\hline III & $105(54.7)$ \\
\hline IV & $62(32.3)$ \\
\hline Head and neck AIS $\geq 3, n(\%)$ & $52(27.1)$ \\
\hline Chest AIS $\geq 3, n(\%)$ & $105(54.7)$ \\
\hline Abdomen AIS $\geq 3, n(\%)$ & $67(34.9)$ \\
\hline Any surgery, $n(\%)$ & $173(90.1)$ \\
\hline Any surgery within $24 \mathrm{~h}, n(\%)$ & $67(34.9)$ \\
\hline Pelvis surgery within $24 \mathrm{~h}, n(\%)$ & $15(7.8)$ \\
\hline \multicolumn{2}{|l|}{ Outcome } \\
\hline 28-day free ICU stay, median (IQR), days & $21(3-26)$ \\
\hline $\begin{array}{l}\text { 90-day free hospital stay, median (IQR), } \\
\text { days }\end{array}$ & $48(0-63)$ \\
\hline \multicolumn{2}{|l|}{$\mathrm{pRBC}$ transfusion } \\
\hline $\begin{array}{l}\leq 4 \mathrm{~h} \text { pRBC transfusion, median (IQR), } \\
\text { packs }\end{array}$ & $3(1-6)$ \\
\hline $\begin{array}{l}\text { 4-24 h pRBC transfusion, median (IQR), } \\
\text { packs }\end{array}$ & $2(0-4)$ \\
\hline
\end{tabular}

Table 1 (continued)

\begin{tabular}{lc}
\hline Characteristics & Variable \\
\hline 24 h pRBC transfusion, median (IQR), & $5(2-11)$ \\
$\quad$ packs & $13(6.8)$ \\
MT within 4 h $(\geq 10$ packs pRBC), $n(\%)$ & $19(9.9)$ \\
MT between 4-24 h ( $\geq 10$ packs pRBC), $n$ & \\
$\quad \%$ ) & $52(27.1)$ \\
MT within 24 h ( $\geq 10$ packs pRBC), $n(\%)$ & $7(3.7)$ \\
Mortality within 24 h, $n(\%)$ & $28(14.6)$ \\
Overall mortality, $n(\%)$ & $7(25)$ \\
Hemorrhage, $n(\%)^{*}$ & $11(39.3)$ \\
Sepsis or organ failure, $n(\%)^{*}$ & $8(28.6)$ \\
Traumatic brain injury, $n(\%)^{*}$ & $2(7.1)$ \\
Others, $n(\%)^{*}$ &
\end{tabular}

Values are presented as numbers (\%) or medians (interquartile range) $I Q R$ interquartile range, $T A$ traffic accident, ISS Injury Severity Score, GCS Glasgow Coma Scale, RTS Revised Trauma Score, AIS Abbreviated Injury Scale, TRISS Trauma and Injury Severity Score, WSES World Society of Emergency Surgery, $p R B C$ packed red blood cells, $I C U$ intensive care unit, $M T$ massive transfusion

*Attributable percentage of total mortality

\section{Secondary outcomes of patients according to DTE time}

Multiple linear regression analyses were performed to evaluate the effects of DTE time on pRBC transfusion requirement in the initial $24 \mathrm{~h}$, ICU-free days to day 28 , and hospital-free days to day 90. DTE time was an independent indicator of $24 \mathrm{~h} \mathrm{pRBC}$ transfusion requirement and ICU-free days to day 28 ( $p=0.012$ and 0.025 , respectively; Table 3). Figure 4 shows the positive relationship between DTE time and pRBC transfusion amounts in the initial $24 \mathrm{~h}$ and the negative relationship between DTE time and ICU-free days to day 28. However, no significant difference in hospital-free days to day 90 was found. Similarly, overall mortality was not significantly different in multiple logistic regression analyses (adjusted $\mathrm{OR}=1.28,95 \%$ $\mathrm{CI}=0.97-1.68, p=0.082$ ).

\section{Subgroup analyses: clinical outcomes according to DTE time ( $\leq 150 \mathrm{~min}$ vs. $>150 \mathrm{~min}$ )}

We divided the patients into two groups according to their DTE time to assess the effects of this factor on clinical outcomes. We set the cut-off point as $150 \mathrm{~min}$, which was the median DTE time. Figure 5 shows the Kaplan-Meier 28-day mortality curves of patients undergoing TAE according to DTE time. The incidence of 28-day mortality was significantly lower in patients with DTE time $\leq 150$ min than in patients with DTE time $>150 \min (p=0.023)$ and a similar result remained even after we divided patients into three 
Table 2 Univariable and multiple logistic regression analyses for mortality in the first $24 \mathrm{~h}(n=192)$

\begin{tabular}{|c|c|c|c|c|}
\hline Variable & Crude odds ratio $(95 \% \mathrm{CI})$ & $p$ value & $\begin{array}{l}\text { Adjusted odds ratio* } \\
(95 \% \mathrm{CI})\end{array}$ & $p$ value \\
\hline Door-to-embolization time, median (IQR), $\mathrm{h}$ & $1.68(1.19-2.38)$ & 0.003 & $2.00(1.20-3.34)$ & 0.008 \\
\hline Door-to-angiography time, median (IQR), h & $1.74(1.22-2.48)$ & 0.002 & & \\
\hline Age, median (IQR), years & $1.00(0.94-1.07)$ & 0.908 & & \\
\hline Female, $n(\%)$ & $0.60(0.05-6.71)$ & 0.678 & & \\
\hline \multicolumn{5}{|l|}{ Physiology at admission } \\
\hline Systolic blood pressure, median (IQR), $\mathrm{mmHg}$ & $0.97(0.95-1.00)$ & 0.120 & & \\
\hline Heart rate, median (IQR), beats/min & $0.94(0.91-0.98)$ & 0.003 & & \\
\hline Hemodynamic instability, $n(\%)$ & $0.85(0.07-9.54)$ & 0.895 & & \\
\hline Lactic acid, median (IQR), mmol/L & $1.10(0.96-1.27)$ & 0.179 & & \\
\hline Base excess, median (IQR) & $0.88(0.76-1.01)$ & 0.075 & & \\
\hline ISS, median (IQR) & $1.12(0.99-1.25)$ & 0.062 & & \\
\hline GCS, median (IQR) & $0.73(0.56-0.97)$ & 0.027 & $0.63(0.40-0.98)$ & 0.040 \\
\hline RTS, median (IQR) & $0.99(0.44-2.22)$ & 0.987 & & \\
\hline TRISS, median (IQR) & $0.003(0.000-0.466)$ & 0.023 & & \\
\hline Head and neck AIS $\geq 3, n(\%)$ & $1.35(0.12-15.24)$ & 0.807 & & \\
\hline Chest AIS $\geq 3, n(\%)$ & $1.67(0.15-18.73)$ & 0.678 & & \\
\hline Abdomen AIS $\geq 3, n(\%)$ & $3.81(034-42.87)$ & 0.278 & & \\
\hline pRBC transfusion within $24 \mathrm{~h}$, median (IQR), packs & $1.05(1.01-1.09)$ & 0.013 & & \\
\hline
\end{tabular}

Values are presented as numbers (\%) or medians (interquartile range)

CI confidence interval, IQR interquartile range, ISS Injury Severity Score, GCS Glasgow Coma Scale, RTS Revised Trauma Score, TRISS Trauma and Injury Severity Score, AIS Abbreviated Injury Scale, $p R B C$ packed red blood cells

*Adjusted odds ratio for age, gender, systolic blood pressure, ISS, GCS, and pRBC transfusion in the initial $24 \mathrm{~h}$

Table 3 Secondary outcomes according to door-to-embolization time $(n=192)$

\begin{tabular}{|c|c|c|c|c|c|c|c|c|}
\hline & $\begin{array}{l}\text { Unstand- } \\
\text { ardized } \\
\text { coefficient }^{\dagger}\end{array}$ & Standard error & $\begin{array}{l}\text { Standardized } \\
\text { coefficients } \\
\text { beta }^{\dagger}\end{array}$ & $p$ value & $\begin{array}{l}\text { Crude OR } \\
(95 \% \mathrm{CI})\end{array}$ & $p$ value & $\begin{array}{l}\text { Adjusted OR } \\
(95 \% \mathrm{CI})^{\ddagger}\end{array}$ & $p$ value \\
\hline $\begin{array}{l}\text { pRBC transfusion require- } \\
\text { ment in the initial } 24 \mathrm{~h}^{*}\end{array}$ & 1.21 & 0.480 & 0.172 & 0.012 & & & & \\
\hline ICU-free days to day $28^{*}$ & -0.921 & 0.407 & -0.138 & 0.025 & & & & \\
\hline Hospital-free days to day $90^{*}$ & -1.519 & 1.142 & -0.087 & 0.185 & & & & \\
\hline Overall mortality $^{*}$ & & & & & $1.29(1.06-1.58)$ & 0.012 & $1.28(0.97-1.68$ & 0.082 \\
\hline
\end{tabular}

$O R$ odds ratio, $C I$ confidence interval, $p R B C$ packed red blood cells, ISS Injury Severity Score, AIS Abbreviated Injury Scale, GCS Glasgow Coma Scale, $R T S$ revised trauma scale

*Door-to-embolization time per $1 \mathrm{~h}$ increase. $†$ Adjusted coefficient for ISS, age, hemodynamic instability, and AIS for pelvic ring fracture. fadjusted odds ratio for base excess, ISS, GCS, TRISS and pRBC transfusion in the initial $24 \mathrm{~h}$

groups according to their DTE time ( $\leq 150$ vs. $150-300$ vs. $>300$ min; $p<0.001$; Fig. 5).

\section{Discussion}

The main findings of this study are that a shorter DTE time was associated with a lower risk for mortality in the first $24 \mathrm{~h}$. In addition, DTE time was an independent predictor of requirement for pRBC transfusion in the initial $24 \mathrm{~h}$ and
ICU-free days to day 28. However, no benefits of reducing DTE time were apparent in terms of overall mortality or hospital-free days to day 90 .

\section{Comparison with other studies}

The cause of early mortality was often haemorrhage, whereas the cause of late mortality was sepsis/organ failure or traumatic brain injury. Thus, we did not choose survival-to-discharge but instead survival in the first $24 \mathrm{~h}$ 

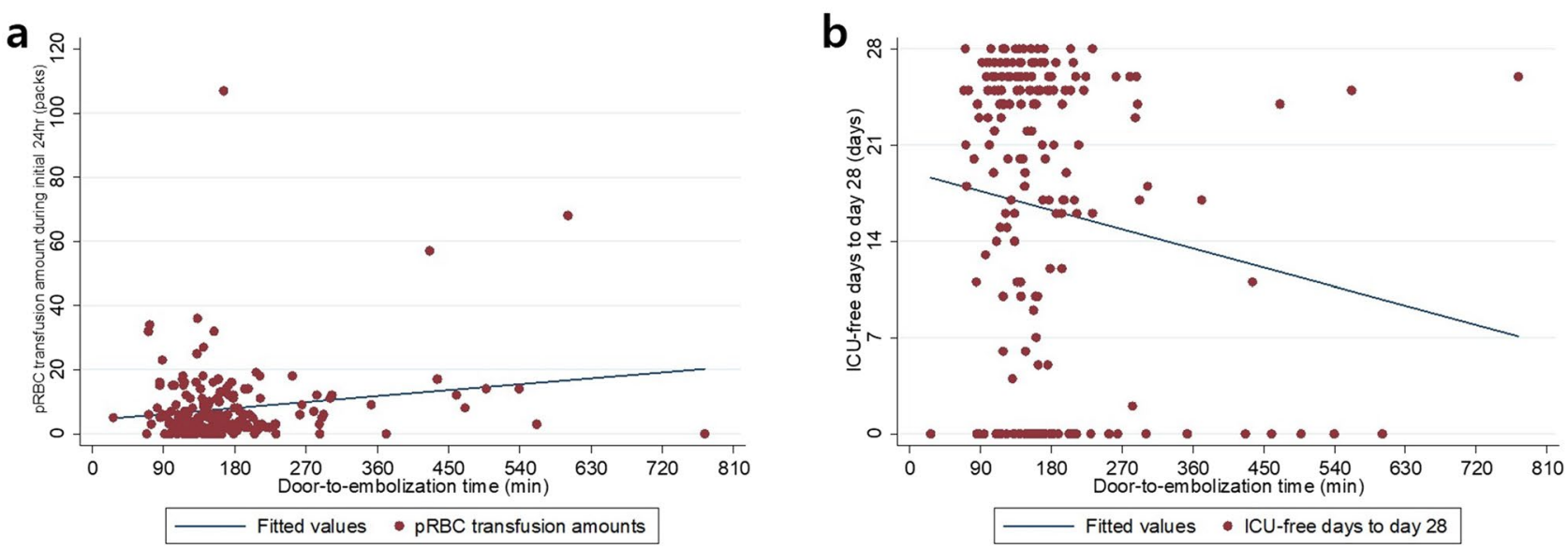

Fig. 4 Relationships between a door-to-embolization time and the requirement for packed red blood cells transfusion requirement in the initial $24 \mathrm{~h}$, and $\mathbf{b}$ door-to-embolization time and ICU-free days to day 28. $p R B C$ packed red blood cells
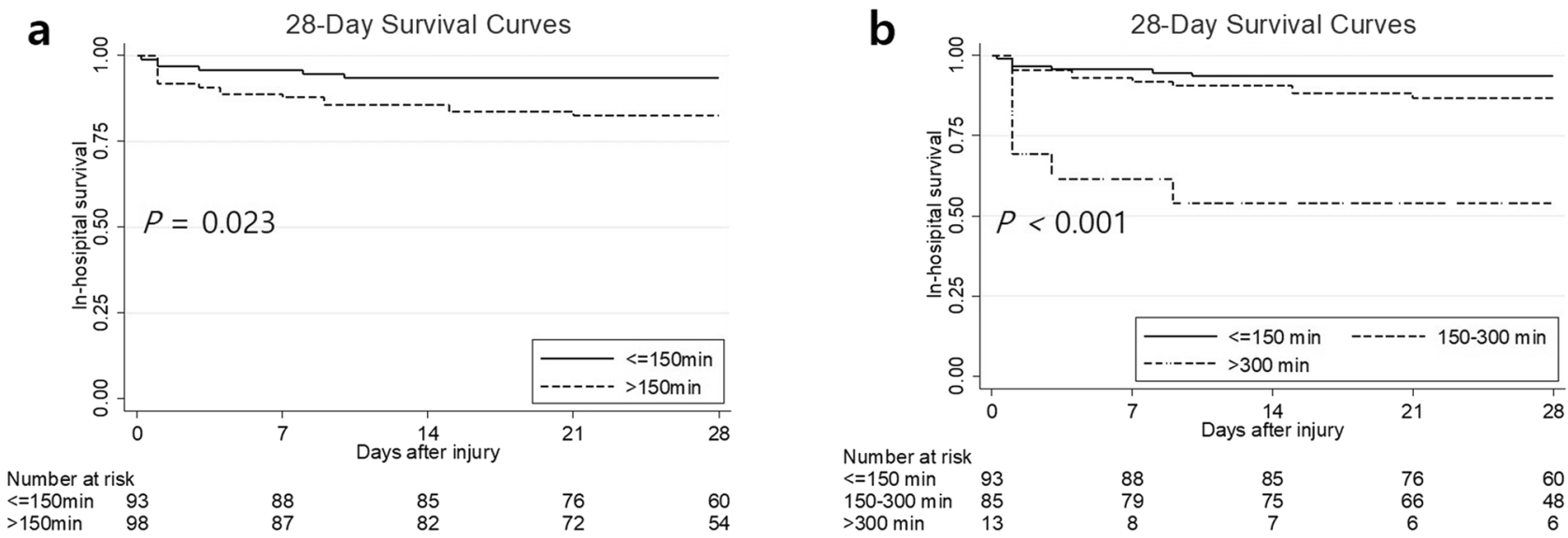

Fig. 5 Kaplan-Meier 28-day mortality curves of patients treated with transarterial embolization according to door-to-embolization time

as a primary outcome to distinguish deaths due to bleeding from others. Early angiography with embolization, when needed, has been shown to improve patient survival [6,20, $21]$, and several studies support this hypothesis [10-13, 22]. On the other hand, some have reported that there are no significant differences in DTE time between nonsurviving and surviving patients $[14,15]$. Table 4 shows a summary of reported series about the impact of DTE time on the mortality of patients with pelvic fracture undergoing TAE [10-15, 22]. In our study, shortening DTE time was associated with better survival in the first $24 \mathrm{~h}$ as well as other clinical outcomes in patients with complex pelvic fracture undergoing TAE. Early access to angiography is associated with reduced mortality. Longer DTE time is associated with worse outcomes [10-15, 22]. Therefore, efforts to minimize DTE time are recommended to improve clinical outcomes in patients with pelvic fracture treated with TAE [6, 14]. Recently, Ito et al. [23] reported that a hybrid emergency room system improved the timeliness of TAE for pelvic fracture.

In this study, we further analyzed how DTE time affected the requirement for $\mathrm{pRBC}$ transfusion, ICU-free days to day 28 , and hospital-free days to day 90 . We found that there were trends in which increasing DTE time resulted in both a higher requirement for $24 \mathrm{~h}$ pRBC transfusion and fewer ICU-free days to day 28; the data in Table 3 and Fig. 4 show these two relationships. These results support other results that shortening DTE reduces the $24 \mathrm{~h}$ transfusion requirement and ICU length of stay $[12,14]$.

\section{Implications of study}

There are three main differences between our study and other studies that have suggested that shortening DTE time might be associated with better clinical outcomes. First, we clearly defined DTE and DTA times; we believe that these 
Table 4 Summary of reported series about the impact of door-to-embolization time on the mortality of patients with pelvic fracture undergoing transarterial embolization

\begin{tabular}{|c|c|c|c|c|}
\hline Study citation (year) & $\begin{array}{l}\text { No. of } \\
\text { TAE } \\
\text { cases }\end{array}$ & Outcome variable & Time (min) & Impact on mortality \\
\hline Agolini et al. [11] & 15 & $\begin{array}{l}\text { Time from arrival to angiography } \\
\text { suite }\end{array}$ & $190 \min (\mathrm{IQR}, 50-1440)$ & $\begin{array}{l}\text { Patients who were in the angiogra- } \\
\text { phy suite within } 3 \mathrm{~h} \text { of arrival had } \\
\text { a significantly greater survival rate } \\
(14 \mathrm{vs} .75 \%)\end{array}$ \\
\hline Balogh et al. [12] & 31 & DTA time & $<90$ min after admission & $\begin{array}{l}\text { Institutional protocol improving } \\
\text { time to angiography to less than } \\
90 \text { min decreased mortality from } \\
35 \text { to } 7 \%(p<0.05)\end{array}$ \\
\hline Schwartz et al. [22] & 88 & $\begin{array}{l}\text { Time from admission to angiogra- } \\
\text { phy suite }\end{array}$ & $\begin{array}{l}\text { Day: } 193 \text { min (IQR, 137-275), } \\
\text { after-hours: } 301 \min (\mathrm{IQR}, \\
\text { 211-389) }\end{array}$ & $\begin{array}{l}\text { Delays to angiography in after-hours } \\
\text { admission were associated with } \\
\text { higher mortality ( } 32 \text { vs. } 21 \% \text {, } \\
p=0.328 \text { ) }\end{array}$ \\
\hline Tanizaki et al. [13] & 68 & $\begin{array}{l}\text { Time from arrival to angiography } \\
\text { suite }\end{array}$ & Average of $76 \min (30-145)$ & $\begin{array}{l}\text { Patients who were embolized within } \\
60 \text { min of arrival had a signifi- } \\
\text { cantly lower mortality rate (16 vs. } \\
64 \%, p=0.04 \text { ) }\end{array}$ \\
\hline Tesoriero et al. [15] & 212 & DTA time & $280 \min (\mathrm{IQR}, 201-367)$ & $\begin{array}{l}\text { Time to angiography was not a } \\
\text { significant contributor to mortality } \\
\text { after adjusting for injury severity }\end{array}$ \\
\hline Marsushuma et al. [10] & 181 & DTE time & (Not applicable) & $\begin{array}{l}\text { A longer time to TAE was signifi- } \\
\text { cantly associated with increased } \\
\text { in-hospital mortality }(\mathrm{OR}=1.79 \\
\text { for each hour, } 95 \% \mathrm{CI}=1.12-2.91 \text {, } \\
p=0.018)\end{array}$ \\
\hline Chou et al .[14] & 84 & DTE time & $62.0 \pm 33.4 \mathrm{~min}$ & $\begin{array}{l}\text { There were no significant dif- } \\
\text { ferences in the time to TAE } \\
\text { between nonsurviving and } \\
\text { surviving patients }(76.9 \pm 47.9 \text { vs. } \\
59.0 \pm 29.3 \text { min, } p=0.068)\end{array}$ \\
\hline This study (2020) & 204 & DTE time & $150 \min (\mathrm{IQR}, 123-186)$ & $\begin{array}{l}\text { An increase in } 1 \mathrm{~h} \text { in door-to- } \\
\text { embolization time resulted in a } \\
2.00 \text {-fold increase in mortality in } \\
\text { the first } 24 \mathrm{~h}(p=0.008)\end{array}$ \\
\hline
\end{tabular}

$T A E$ transarterial embolization, $I Q R$ interquartile range; $D T A$ door to angiography, DTE door to embolization, NA not applicable, $O R$ odds ratio, CI confidence interval

should be clearly distinguished because of their different effects on the clinical outcomes. However, many studies did not have a clearly defined DTE or DTA, and the two occasionally appeared to be used interchangeably [10-15, 22]. By contrast, we clearly defined DTE time as that from arrival at hospital to the first application of embolic agents to pelvic arteries and DTA time as that from arrival at hospital to the beginning of angiography. The current study showed that there was a continuous association between shortening DTE time and reduced risk for mortality. Second, our study suggested that shortening DTE time could reduce patients' mortality rate as well as other outcomes, such as blood transfusion requirement and ICU length of stay. On the other hands, other study showed only reduced mortality or reduced transfusion require or decreased hospital stay $[10-15,22]$. We thought major novelty of this study was the impact of shorter DTE time on various clinical outcomes in patients with complex pelvic fracture who underwent TAE. Third, the median DTE time in this study was shorter than that in other studies. Despite the suggestion that short DTE time improves mortality, some reported series document considerable delays. Gannslen et al. [24] reported that the average DTE time was $10.7 \mathrm{~h}$. Tesoriero et al. [15] reported that the median time to embolization was $344 \mathrm{~min}(4.7 \mathrm{~h})$. Evers et al. [25] reported that the mean time from admission to angiography was more than $4 \mathrm{~h}$. By contrast, the median DTA time in our study was $107 \mathrm{~min}(1.8 \mathrm{~h})$ and the median DTE time was $150 \mathrm{~min}(2.5 \mathrm{~h})$. In addition, the DTA time was not significantly different between daytime and nighttime (98 min [IQR, 73-134] vs. $112 \mathrm{~min}$ [IQR, 86-135], $p=0.067)$ or between weekday and weekend or holiday (101 $\mathrm{min}$ [IQR, 77-133] vs. $113 \mathrm{~min}$ [IQR, 83-139], 
$p=0.156)$. Our three interventional radiologists and the equipment required for TAE are available around the clock [16]. Thus, we believe that DTA time and DTE time can be shortened and our results indicate that patients with a short DTE time $(\leq 150 \mathrm{~min})$ achieved better clinical outcomes.

\section{Limitations of study}

There were two limitations of this study. First, it was confined to patients at a single center and our study population may not represent general patients with pelvic fracture. For example, our study population consisted of polytraumatic patients who did not undergo PPP and/or pelvic fixation and was limited to complex pelvic fracture (WSES grade $\geq$ II) [7], which may limit the generalizability of our findings. Second, because this was a non-randomized, retrospective analysis, the results are not conclusive. Additional, prospective, randomized, controlled trials with a larger sample size are necessary to verify our findings.

\section{Conclusion}

Shorter DTE time was associated with better clinical outcomes in patients with complex pelvic fracture who underwent TAE. These findings suggest that shortening DTE time could reduce patients' mortality rate as well as other outcomes, such as blood transfusion requirement and ICU length of stay. Thus, DTE time is an important factor to consider when treating patients with suspected pelvic hemorrhage. Efforts to minimize DTE time are recommended to improve the clinical outcomes in patients with pelvic fracture treated with TAE.

\section{Compliance with ethical standards}

Conflict of interest The authors declare that they have no competing interests.

Ethics approval and consent to participate This retrospective study was approved by the Institutional of Review Board of Pusan National University Hospital (H-2004-017-090)

Consent for publication All authors agree with the publication of this article.

Open Access This article is licensed under a Creative Commons Attribution 4.0 International License, which permits use, sharing, adaptation, distribution and reproduction in any medium or format, as long as you give appropriate credit to the original author(s) and the source, provide a link to the Creative Commons licence, and indicate if changes were made. The images or other third party material in this article are included in the article's Creative Commons licence, unless indicated otherwise in a credit line to the material. If material is not included in the article's Creative Commons licence and your intended use is not permitted by statutory regulation or exceeds the permitted use, you will need to obtain permission directly from the copyright holder. To view a copy of this licence, visit http://creativecommons.org/licenses/by/4.0/.

\section{References}

1. Costantini TW, Coimbra R, Holcomb JB, Podbielski JM, Catalano $\mathrm{R}$, Blackburn A, et al. Current management of hemorrhage from severe pelvic fractures: results of an American Association for the Surgery of Trauma multi-institutional trial. J Trauma Acute Care Surg. 2016;80(5):717-23. https://doi.org/10.1097/TA.00000 00000001034 (discussion 23-5).

2. Ghaemmaghami V, Sperry J, Gunst M, Friese R, Starr A, Frankel $\mathrm{H}$, et al. Effects of early use of external pelvic compression on transfusion requirements and mortality in pelvic fractures. Am J Surg. 2007;194(6):720-3. https://doi.org/10.1016/j.amjsu rg.2007.08.040.

3. Hauschild O, Aghayev E, von Heyden J, Strohm PC, Culemann $\mathrm{U}$, Pohlemann T, et al. Angioembolization for pelvic hemorrhage control: results from the German pelvic injury register. J Trauma Acute Care Surg. 2012;73(3):679-84. https://doi.org/10.1097/ TA.0b013e318253b5ba.

4. White CE, Hsu JR, Holcomb JB. Haemodynamically unstable pelvic fractures. Injury. 2009;40(10):1023-30. https://doi. org/10.1016/j.injury.2008.11.023.

5. Salcedo ES, Brown IE, Corwin MT, Galante JM. Pelvic angioembolization in trauma-indications and outcomes. Int J Surg. 2016;33:231-6. https://doi.org/10.1016/j.ijsu.2016.02.057.

6. Vaidya R, Waldron J, Scott A, Nasr K. Angiography and embolization in the management of bleeding pelvic fractures. J Am Acad Orthop Surg. 2018;26(4):e68-76. https://doi.org/10.5435/JAAOS -D-16-00600.

7. Coccolini F, Stahel PF, Montori G, Biffl W, Horer TM, Catena $F$, et al. Pelvic trauma: WSES classification and guidelines. World J Emerg Surg. 2017;12:5. https://doi.org/10.1186/s1301 7-017-0117-6.

8. Cullinane DC, Schiller HJ, Zielinski MD, Bilaniuk JW, Collier BR, Como J, et al. Eastern Association for the Surgery of Trauma practice management guidelines for hemorrhage in pelvic fracture-update and systematic review. J Trauma. 2011;71(6):1850 68. https://doi.org/10.1097/TA.0b013e31823dca9a.

9. Chu CH, Tennakoon L, Maggio PM, Weiser TG, Spain DA, Staudenmayer KL. Trends in the management of pelvic fractures, 2008-2010. J Surg Res. 2016;202(2):335-40. https://doi. org/10.1016/j.jss.2015.12.052.

10. Matsushima K, Piccinini A, Schellenberg M, Cheng V, Heindel P, Strumwasser A, et al. Effect of door-to-angioembolization time on mortality in pelvic fracture: every hour of delay counts. J Trauma Acute Care Surg. 2018;84(5):685-92. https://doi.org/10.1097/ TA.0000000000001803.

11. Agolini SF, Shah K, Jaffe J, Newcomb J, Rhodes M, Reed JF 3rd. Arterial embolization is a rapid and effective technique for controlling pelvic fracture hemorrhage. J Trauma. 1997;43(3):395-9. https://doi.org/10.1097/00005373-199709000-00001.

12. Balogh Z, Caldwell E, Heetveld M, D'Amours S, Schlaphoff $\mathrm{G}$, Harris I, et al. Institutional practice guidelines on management of pelvic fracture-related hemodynamic instability: do they make a difference? J Trauma. 2005;58(4):778-82. https://doi. org/10.1097/01.ta.0000158251.40760.b2.

13. Tanizaki S, Maeda S, Matano H, Sera M, Nagai H, Ishida H. Time to pelvic embolization for hemodynamically unstable pelvic fractures may affect the survival for delays up to $60 \mathrm{~min}$. Inj Int J Care Inj. 2014;45(4):738-41. https://doi.org/10.1016/j.injur y.2013.11.007. 
14. Chou $\mathrm{CH}$, Wu YT, Fu CY, Liao CH, Wang SY, Bajani F, et al. Hemostasis as soon as possible? The role of the time to angioembolization in the management of pelvic fracture. World J Emerg Surg. 2019;14:28. https://doi.org/10.1186/s13017-019-0248-z.

15. Tesoriero RB, Bruns BR, Narayan M, Dubose J, Guliani SS, Brenner ML, et al. Angiographic embolization for hemorrhage following pelvic fracture: Is it "time" for a paradigm shift? J Trauma Acute Care Surg. 2017;82(1):18-26. https://doi.org/10.1097/ TA.0000000000001259.

16. Lee R, Jeon CH, Kim CW, Kwon H, Kim JH, Kim H, et al. Clinical results of distal embolization in grade $\mathrm{V}$ splenic injury: fouryear experience from a Single Regional Trauma Center. J Vasc Interv Radiol. 2020;31(10):1050-7.e2. https://doi.org/10.1016/j. jvir.2020.01.029 (Epub 2020 Apr 25).

17. American College of Surgeons Committee on Trauma. Advanced Trauma Life Support student course manual. 10th ed. Chicago: American College of Surgeons; 2018. p. 52-4.

18. Morozumi J, Homma H, Ohta S, Noda M, Oda J, Mishima S, et al. Impact of mobile angiography in the emergency department for controlling pelvic fracture hemorrhage with hemodynamic instability. J Trauma. 2010;68(1):90-5. https://doi.org/10.1097/ TA.0b013e3181c40061.

19. Loggers SAI, Koedam TWA, Giannakopoulos GF, Vandewalle E, Erwteman M, Zuidema WP. Definition of hemodynamic stability in blunt trauma patients: a systematic review and assessment amongst Dutch trauma team members. Eur J Trauma Emerg Surg. 2017;43(6):823-33. https://doi.org/10.1007/s00068-016-0744-8.

20. Costantini TW, Bosarge PL, Fortlage D, Bansal V, Coimbra R. Arterial embolization for pelvic fractures after blunt trauma: are we all talk? Am J Surg. 2010;200(6):752-7. https://doi. org/10.1016/j.amjsurg.2010.06.006 (discussion 7-8).

21. Hak DJ, Smith WR, Suzuki T. Management of hemorrhage in life-threatening pelvic fracture. J Am Acad Orthop Surg. 2009;17(7):447-57. https://doi.org/10.5435/00124635-20090 7000-00005.

22. Schwartz DA, Medina M, Cotton BA, Rahbar E, Wade CE, Cohen $\mathrm{AM}$, et al. Are we delivering two standards of care for pelvic trauma? Availability of angioembolization after hours and on weekends increases time to therapeutic intervention. J Trauma Acute Care Surg. 2014;76(1):134-9. https://doi.org/10.1097/ TA.0b013e3182ab0cfc.

23. Ito K, Nagao T, Tsunoyama T, Kono K, Tomonaga A, Nakazawa $\mathrm{K}$, et al. Hybrid emergency room system improves timeliness of angioembolization for pelvic fracture. J Trauma Acute Care Surg. 2020;88(2):314-9. https://doi.org/10.1097/TA.000000000000254 4.

24. Gansslen A, Giannoudis P, Pape HC. Hemorrhage in pelvic fracture: who needs angiography? Curr Opin Crit Care. 2003;9(6):515-23. https://doi.org/10.1097/00075198-20031200000009.

25. Evers BM, Cryer HM, Miller FB. Pelvic fracture haemorrhage. Priorities in management. Arch Surg. 1989;124(4):422-4. https ://doi.org/10.1001/archsurg.1989.01410040032006. 